\title{
IMPROVING QUALITY OF MEETINGS USING MUSIC
}

\author{
Author Details \\ CAROLINE VAN NIEKERK (Prof) \\ Department of Music \\ University of Pretoria \\ Pretoria \\ South Africa \\ ROY PAGE-SHIPP (Mr) \\ Gordon Institute of Business Science \\ University of Pretoria \\ Pretoria \\ South Africa
}

Corresponding Author: Caroline van Niekerk

Corresponding Author's Email: caroline@ mweb.co.za

Key words: Humour, Meetings, Mood, Music, Quality, Stress release, Singing, Tribal glue, Trust.

\begin{abstract}
Music's power in leadership and the development of trust has been both recognised and documented at least since the time of the Ancient Greeks. The potential impact of faceto-face meetings, as opposed to communication by other means - even aided by a battery of technological developments - is also widely accepted. The authors argue that modern quality-driven managers are missing a significant opportunity by their apparent failure to perceive and exploit the synergy between these two elements.

The article commences by tracing the history of the use of music and its influence on inter-personal behaviour. It continues by exploring the various attributes of music that can be brought to bear on improving quality in meetings. Finally it describes the many tools and opportunities that managers have to exploit the power of music in targeting greater efficiency in communication, cognition and cooperation among quality-focused teams.
\end{abstract}




\section{INTRODUCTION}

"...Vaw dine sanf tur fle...ee gil vilet!" ("Wo dein sanfter Fluegel weilt', in the original German.) The strains of the Ode to Joy from Beethoven's $9^{\text {th }}$ Symphony fade away and an audience of 150 middle and senior managers look at each other in some astonishment. They have just been induced - all of them! - by Ben Zander to sing, lustily and in unison, a phonetic version of this famous piece distributed to them on printed sheets. A very good presentation on his 'Art of Possibility' theme has been transformed into a memorable - and perhaps life-changing - experience.

Zander is the conductor of the Boston Philharmonic Orchestra and the co-author of The Art of Possibility (Zander \& Zander, 2000). Much of Zander's success as a speaker on passion and motivation comes from his ability to capture the attention of not-verymusical audiences by illustrations from his experience as a conductor.

Many of those attending might have been nervous of coming to a lecture, even by a celebrated visitor, had they known that they would be expected to sing! But it has happened, in a legitimate 'management' setting, and they have been exhilarated by the quality of the experience: so TQM and music need not be unfamiliar bedfellows.

From the earliest days of homo sapiens there is good evidence that music has been important, among other instances in establishing leadership and in the development of trust. Meetings provide ample opportunities to achieve both these contributions to TQM, and yet the use of music by especially Caucasian leaders in meetings seems largely neglected. In a recent 'dipstick' study among male singing groups in Pretoria, South Africa, only about half the respondents had used their voices in a work situation and only two thirds of these did so regularly. ${ }^{1}$ If this was the case with subjects who regularly use their voices in public performance, one must expect the general incidence to be considerably lower, and this, indeed, is one's anecdotal experience. A likely reason for this decline is found in the worldwide experience of musicians and music educators, who complain that at government and policy levels and from the side of Education Departments ${ }^{2}$ in particular, music is regarded as a "frill"/a nice to have, but not a necessary to have; even as nothing more than auditory cheesecake and the biologically useless "making of plinking noises", according to Pinker (1997) in his book How the Mind Works (p. 528). Although singing in the classroom remains a frequent feature of the earliest school years, most schools do not continue to provide music in the curriculum later, nor do they offer music as an examination subject.

\section{QUALITY IN MEETINGS AND THE NEGLECT OF MUSIC}

Is there possibly time for this apparently leisure focused activity, in the world of work? After all, one "plays" music or "makes" music; one does not "work" music.

\footnotetext{
${ }^{1}$ Page-Shipp and van Niekerk, to be published.

${ }^{2}$ The withdrawal of funding for crusading violin teacher Roberta Guaspari's programme in East Harlem was the background to Meryl Streep's 1999 movie 'Music of the Heart'.
} 
On the other hand, there are well-known accusations that meetings ${ }^{3}$ can be extremely inefficient, taking an inordinate amount of simultaneous time from high-level personnel. Duffy and McEuen (2010), however, quote from a study of 750 US executives that "there is an excellent ROI for face-to-face meetings and ... executives prefer them to virtual meetings". Surely the possibility of enhancing the quality of such a high-cost activity should be worthwhile? And from a specific TQM perspective, meetings are an important vehicle for teaching and promoting concepts of quality in the workplace.

We commence with a review of the evolution of music-making by humans, and question why something as natural as music-making has declined in Western society. What is known about music (and management) behaviour is explored and some suggestions are made as to how appropriate musical interventions in meetings can be mould-breaking. Hopefully this will inspire general managers, driven to improve Quality in all spheres of operations, to experiment with these interventions and learn more of their utility.

\section{MUSIC AND HUMAN BEHAVIOUR IN HISTORY}

Seeking to justify music's use and importance by quoting well known authorities within the field of music may seem egregiously self-serving. But, scanning more broadly than the Zander episode described above, one can profitably turn for justification to specialists who are non-musicians, noting that, since the time of the early cultural anthropologist Margaret Mead (born 1901), claims have been made that the appreciation of music is a universal feature of humankind: music-making is found in all societies and it is normal for everyone to participate in some manner. This article draws heavily on the deep insights and prodigious research that led to the 2005 book The Singing Neanderthals by Steven Mithen, Head of the School of Human and Environmental Sciences at the University of Reading (Mithen, 2005, p.1). He notes that "the modern-day West is quite unusual in having significant numbers of people who do not actively participate and may even claim to be unmusical ... we can only explain the human propensity to make and listen to music by recognising that it has been encoded into the human genome during the evolutionary history of our species."

Music in the modern world is ubiquitous, not only in terms of background music in public places, but also via iPods, in-vehicle sound systems, and directly off one's PC. The renowned social anthropologist John Blacking (1973) remarked that "society claims that only a limited number of people are musical, and yet it behaves as if all possessed the basic capacity without which no musical tradition can exist - the capacity to listen and distinguish patterns of sound". A society in which commuters and gym patrons commonly wear earphones to provide a personalised musical programme can hardly be called 'unmusical!

Mithen (2005, p.vii) describes our "propensity to make music (as) the most mysterious, wonderful and neglected feature of humankind". His book explains his theory as to why

\footnotetext{
${ }^{3}$ The term is used here in the broad sense of any assembly or gathering of people, and so can encompass conferences, congresses, seminars, etc. Later suggestions will include proposals for improving the effectiveness of management meetings, per se.
} 
people should feel themselves so compelled to make and listen to music. He draws together and explains connections between the evidence to have emerged from archaeology, anthropology, psychology, neuroscience and, of course, musicology, in addition to other disciplines, and then notes: "I came to appreciate that it was not only music I was addressing but also language: it is impossible to explain one without the other". Of course meetings par excellence make use of language.

Language has a self-evident function ... but what is the 'point' of music? Reimer (2003, p.42) provides a clear answer: "If all meanings could be adequately expressed by words, the arts of painting and music would not exist. There are values and meanings that can be expressed only by immediately visible and audible qualities". Of course language chiefly conveys information, but the rhythms that make some speakers more easy on the ear have a common origin with music. In the context of meetings the emphasis on face-to-face contact or at least video conferencing is not only for information exchange, but because of the added knowledge gained from the more feelingful aspects such as accompanying facial expression and body language. And clearly with feelingful, emotional aspects music can play a major role.

\section{WHAT IS MUSIC AND HOW DOES IT INFLUENCE BEHAVIOUR?}

"While the concept of music may vary, all cultures have song and dance, and make some form of internal repetition and variation in their musical utterances; they use rhythmic structures based on distinctions between note lengths and dynamic stresses" (Mithen, 2005, p.12 quoting Nettl, 1983). Much has been written about what are described as cultural and musical "universals", but are there actually such universals? This is exceedingly important to ascertain, in the context of ever-increasing cross- and multiculturalism, including in meetings around the world. Green $(2012$, p141) cites studies reported by Dahlgaard, Pettersen \& Dahlgaard-Park (2011), Chung, Hsu \& Tsai (2010) and Prajogo \& McDermott (2005) to support his contention that "a model of cultural traits ... could give management clues as to the potential for success or failure in TQM interventions within ... organisations."

According to the ethnomusicologist David McAllester (1971), one of the most important of the universals, or near-universals, in music is that music transforms experience ... from the humdrum, the everyday, into something else. Music may heighten excitement or it may soothe tensions, but in either case it takes one away into another state of being ... Music is used in theater, it is used in movies, it is used to ratify revolutions. In all the ways it is used it seems to heighten experience ... We are not all practicing mystics and most of us do not experience God easily. But when we hear music, something like that is happening to us ... Other experiences transform our lives, but none so 'universally.' A few years ago I heard Abraham Maslow describing his research in what he called the 'peak experiences* in human lives. In the course of many hundreds of case histories the two kinds of experience cited far more than any others were sex and music. It takes no temerity, then, to assert that we are studying one of the most 
important of man's activities and one gauge of its importance is the universality, or near-universality of its effect on the human mind.

* The oft-quoted psychologist Mihaly Czicksentmihaly (1990) labels these "flow" experiences.

The above cover a wide range of behavioural impacts. This article focuses on the following five aspects and uses of music, each of which can be profitably utilised in the context of meetings:

- Emotion and mood (constituting by far the most documented aspect)

- Tribal glue ${ }^{4}$ and Trust (especially for team building)

- Cognition

- Movement and stress release

- Humour.

These five are essentially complementary and frequently overlap: in the following treatment they will thus not always be isolated.

\section{Emotion and mood}

'Music has charms to soothe a savage breast/To soften rocks, or bend a knotted oak' claimed the seventeenth-century poet William Congreve. Few would disagree: regardless of personal taste, music moves us, it is chiefly about expressing and inducing emotion, yet surprisingly the scientific study of the relationship between music and emotion to date has been limited.

Both music and language have the quality of expressive phrasing (Mithen, 2005, p.24, quoting Brown, 2000). The cognitive demands of music may be fewer than those of language. Especially non-musicians can simply relax, allowing music to 'wash over' them without having to concentrate or actively listen. Yet even such background music has both cognitive and physiological impacts: as we automatically infer fellow meeting participants' thoughts when listening to their spoken utterances, we equally automatically have our own emotions aroused while listening to music: music often manipulates our mood.

Apart from musical universals, it is now recognized that some emotions are also universal, and not only cultural constructs that are specific to particular societies (Mithen, 2005 , p. 86, quoting Ekman, 1992). Emotions guide action in 'bounded rationality' situations of imperfect knowledge and multiple, conflicting goals. Emotions alter our brain states, making available repertoires of actions previously useful in similar circumstances. We set ourselves goals and sub-goals when undertaking any task, consciously or subconsciously - including in meetings. We feel satisfied by achieving these goals, and this acts as an emotional signal to continue with the task. Emotions are thus critical to 'rational' thought and our interactions with the physical and social worlds. Does this not make one think of meetings?

\footnotetext{
${ }^{4}$ This term is used to signify the ways in which music can be used as a bonding agent within the sorts of communities which successful meetings can, in effect, establish.
} 
"... music is a social product, social resource, and social practice. As such it is not autonomous but is created and performed by real people in particular times and places; in doing so they reveal much about themselves and their societies" (Martin, 1995, p. ii). It is the social world which provides the greatest cognitive challenge to human beings: coping with the demands of living in large social groups in fact provides the most likely explanation for the origin of human intelligence. So it is not surprising that one's more complex emotions relate directly to social relationships. "Without these emotions we would be socially inept, unaware of the complexities and subtleties of the world around us, failing dismally in our relationships" (Mithen, 2005, p. 87).

Human emotions have not only evolved so as to enable intelligent action, but also the propensity to express emotions and the ability to interpret such expressions in others. A key means of such expression is the creation of music (Mithen, 2005, p. 89). Subconsciously music might be appraised in the same way as visual stimuli (snakes or spiders, for example), provoking emotional responses. Music may also cue memories of past emotional experiences, or facilitate empathy for the performer, inter alia via the way in which it is performed; the listeners' states, in terms of their musical expertise, general disposition and current mood; the context in which the music is performed and heard whether a formal occasion or not, whether it occurs without interruption, or any other factors influencing the acoustics and listening experience's ambience (Scherer \& Zentner, 2001).

Emotions, while not to be despised for their stimulating effect, can dominate discussions and decision-making in meetings in less admirable ways. The use of music to 'civilize' the tone of a meeting presents a means of reducing harmful effects.

Mood is different from emotion: the former is a prolonged feeling while the latter may be very short-lived. Specific types of music can induce specific types of mood. Enlightened factory managers play music to improve the morale of employees who have to undertake simple repetitive jobs; dentists and surgeons use music to calm and relax their patients. Psychologists use music when they wish to induce particular moods in their clients prior to setting them an experimental task to complete (Niedenthal \& Setterlund, 1994). Train services can make use of "aural policing ... pump(ing) out Haydn and Mozart to deter vandals and loiterers" (The Economist, 2005). Yes - the mood modification potential of music can be used for a whole range of purposes, including in the context of meetings.

Mood has been shown to influence one's perceptions and judgements of others: evaluations of ourselves are also influenced by our moods, and our emotional states influence the way we think and behave. Experimental demonstration is also available that music can increase cooperation and helpfulness by inducing good moods (Fried \& Berkowitz, 1979) - why not try singing an appropriate song at a tricky point in a meeting? The authors have personally witnessed the effect this had when a colleague and senior manager, confident of his own singing voice, broke into a rendition of a Gilbert and Sullivan song, with its witty words appropriate to the tension being experienced at that point. 
The development and success of music therapy demonstrates further how music can be used to both arouse and express a wide range of emotions, also leading to substantial improvements in mental and physical health. Even without mention of the field of music therapy, much recent research points to the physical benefits of music: improving heart health, lowering cholesterol levels, expanding and clearing blood vessels, increasing endurance, sharpening mental focus and boosting athletic performance (Sunday Times, 2008). But music therapy certainly provides a compelling rebuttal of the claim of Steven Pinker, referred to earlier, that music is biologically useless (Mandel, 1996, p42).

We can readily conclude that music can be used in meetings to arouse emotions or moods that

- stimulate cooperation

- cue memories of past (good) experiences

- civilise the tone of a discussion and

- generally help managers to stimulate cooperation.

\section{Tribal glue and Trust}

"The theme tunes for soap operas illustrate how some pieces of music can have a shared meaning within a single community" (Mithen, 2005, p. 18). Of course, especially at the beginning of meetings, where there is a desire and a need to socialise everyone to 'sing from the same songsheet' (and note that metaphor), one can well consider the use of a musical 'logo', etc. Martin (1995, p. 275) notes: "An adequate understanding of music in modern culture, then, must go beyond the music itself, seeing it as a part - perhaps an essential one - of a much wider cultural configuration ... there is an awareness that the satisfaction of material needs tends to pull people apart from each other, and it is often in music that they seek to repair the social damage."

In all societies music-making is frequently a group activity: music facilitates cooperative activities, with people getting into music together described by musical anthropologist Charles Keil as "the groove" (Keil \& Feld, 1994). But why do people enjoy making music together? Levitin (2010) argues that singing together releases oxytocin - "a neurochemical now known to be involved in establishing bonds of trust between people" (Kosfeld et al., 2005). Releasing oxytocin loosens the synaptic connections in which prior knowledge is held, clearing the way for acquiring new understanding through shared behavioural actions. This is a view of music as the 'biotechnology of group formation'. Regardless of the specific role of oxytocin, many of us have experienced music offering a social rather than a merely individual identity (Menzon, 2001). The conductor of the Scottish Ensemble has provided a beautiful illustration of the role of trust in good musicmaking in his TED talk 'Trusting the ensemble' (Hazlewood, 2011).

Various attempts have been made to explore the role of trust in TQM. Lagrosen and Lagrosen (2012) failed to establish that trust should be included among the traditional core values in TQM, but concluded that it had an important role to play. Dahlgaard-Park (2012) went further and included trust in her Trinity ('3 L') model of human needs, 
placing Trust at the head of a list of 'Spiritual Needs/Core Values under the 'loving' rubric, the other 'Ls' being living and learning.

Other pleasurable activities, such as eating and sex, have obvious pay-offs, but why would music-making have evolved as a pleasurable activity? Yes, it can be used to manipulate others, to transmit information about the natural world, to advertise one's availability to potential mating partners, and to facilitate the cognitive and emotional development of children. But none of these factors explains why music-making in modern human society is predominantly a group activity.

Music-making can be cheap: an easy form of interaction that can demonstrate a willingness to cooperate and thus may promote future cooperation when substantial gains can be made. When people join together for any group activity - a family meal, a football team assembling for a match and, Yes, a meeting with work colleagues - they typically arrive from quite different immediate experiences. A previous work meeting having overrun, one may arrive late for the next one to find some of those waiting are frustrated by one's absence, others are pleased; some are feeling happy because they have had a good day, others are feeling gloomy. In such a situation one has a very profound sense of self, and rapidly puts one's minds to assessing the feelings of others before deciding what to say - at least, one does if the meeting is going to be a success.

Trying to achieve consensus and cooperation with everyone in different moods is always difficult. However, if group norms have been clearly negotiated (see Benson, 1987), making music together can help in such situations, as it will lead to the diminution of strong feelings of self - 'boundary loss'. This is the process in which football crowds, church choirs and children in the playground all engage - be it by mutual consent and understanding or by manipulation. Those making music together mould their minds and bodies into a shared emotional state, and with that comes some loss of self-identity and a concomitant increase in the ability to cooperate with others. In fact, 'cooperate' is not entirely accurate, because as identities merge there is no 'other' to cooperate with, just one group making decisions about how to behave. "Indeed, when psychologists have examined the results of experiments in which people are placed in prisoner's dilemmatype situations, they have concluded that cooperation is fostered by the 'extent to which players come to see themselves as a collective or joint unit ... more formally known ... as an 'in-group biasing effect"' (Caporeal et al, 1989).

We need to be on the look-out for cues prompting group feeling - also in meetings, when consensus - and this does not have to imply groupthink - is being sought. Listening, rather than merely looking, is also useful, because music making together is a key method for creating group identity: "Music is a medium through which individual brains are coupled together in shared activity" (Benzon, 2001).

In the 'Knowledge Society' it has become a commonplace that many of an organisation's knowledge assets reside in the minds of individual staff members (and even of customers and suppliers) (Sveiby, 1997). Access to these assets is obviously dependent on a trust relationship between the owner of the 'mind' and the potential beneficiary of the 
knowledge. This is well summed up by Snowden's (2002) first heuristic: "Knowledge can only be volunteered: it cannot be conscripted." If music can improve trust between colleagues it will enable the freer flow of knowledge and thus result in better informed decision making throughout the organization.

From the above we can conclude that sharing in making music can be a low-cost means of reducing the boundaries between participants, whether they arise from immediate or distant recent experiences, or cultural or other diversity. The outcome is an increase in group trust and a consequential increase in knowledge sharing - crucial in the Knowledge Society.

\section{Cognition}

"The popular characterization of music as the 'language of emotion' is one reason why many modern commentators have been unwilling to accord it much significance.

"Traditionally, the emotions have been thought of as the antithesis of human rationality, our most valued cognitive ability" (Oatley \& Jenkins, 1996). Yet "emotion lies at the root of intelligent action in the world" (Ibid). Fortunately it is widely acknowledged these days that music is critical to the cognitive development of the child (see, for but one reference, Cross, 1999).

Mithen also notes (2005, p. 272) that after language had evolved as the principal communication system of modern humans, people still had the question of who to communicate with through music. He then notes that music can also be a "cognitive anchor" and an extension of the mind; a community can share, by all making the same music, just as they speak the same language. Mithen and Parsons (2008, pp.415-416) note that we "think of brains as providing us with the biological basis of culture in terms of the capacity for making and manipulating artefacts, language, music, dance, and complex social interaction. ... By describing the brain as an artefact of culture we mean that both its anatomy and function have been unintentionally influenced by the cultural contexts in which it has evolved and in which it develops within each individual". One's brain is supposed to function actively during meetings: the relevance of the above quotation and insight is clear in the context of bringing together music and meetings. In spite of being relatively 'information-free', music can add value to comprehension and acceptance of unusual proposals.

Pursuing this theme, the second author has frequently found it possible to use music to make a complex point: e.g. a snatch of 'La donna è mobile' to illustrate the challenge to Guiseppe Verdi of protecting his intellectual property in this potential 'hit' from the Venetian gondoliers overhearing rehearsals at La Fenicè on St Marks' Square. A further application was the use of the music hall song 'If I should plant a tiny seed of love' to characterise Scenario Planning. Finding such 'musical matches' requires time and effort, but the reward is great: all lecturers (and indeed those chairing meetings) watch the faces of their 'audience' to check on impact and not many attention-grabbing devices work better than a few bars of song. The claim that Zander using Beethoven's 'Ode to Joy' made his lecture memorable is not unique. If one wants a group to remember something, 
it would seem obvious to associate it with a well-known piece of music. One has only to think of advertising jingles that continually pop up in one's memory, even from early childhood.

Music can thus improve the focus of meeting participants and their grasp and retention of important information.

\section{Music, movement and stress release}

When we "automatically begin tapping our fingers and toes while listening to music ... even when we sit still, the motor areas of our brain are activated by music" (Janata \& Grafton, 2003). Body movement appears to be as crucial to language as it is to music; the kinaesthetic intelligence as valid as our linguistic and music intelligences. And in meetings, as much as in classrooms of frustrated primary schoolers, forced to sit still on hard school benches, there is a need for physical movement - which can also be greatly enhanced by simultaneous use of music.

The Cape Argus of 16 Aug 2006 contained a Reuters article on "Stressed bankers learn to sing their blues away": - "Stressed bankers in London are being offered a new way to unwind - singing lessons. Professionally trained singer Karin Hochapfel runs stressbusting classes for city high-flyers that use a mixture of yoga, Alexander Technique and breathing exercises to relieve tension - all used by singers to warm up before they perform ... Hochapfel said she sensed people's fear, which she put down to anxiety about doing well in their jobs ... 'All your ligaments are connected to the voice, so the way you hold even your wrists can affect how your voice sounds"'. Great tension reduction can be achieved for attendees of meetings if they have condoned opportunities for stress releasing movement, preferably in combination with music, for its additional positive effects.

Van As investigated choir participation as a means to advance transformation ${ }^{5}$ and team building in a corporate milieu such as Absa Bank. (Choir singing is but one form of musical activity - see also for example aspects such as drum circles for creative team problem solving (http://wilderdom.com/games/InitiativeGames_Other.html). Van As found $(2009$, p. 71$)$ "an improvement in a number of areas significant to develop corporate practices. These include: team building ... attention to detail, improved capacity for listening and greater confidence for social interaction, discipline and enhanced creativity". All of these improvements could be relevant to the context of meetings, too, as they are relevant to "successful implementation of TQM and how organisations can work to achieve homogeneity of values" (Ingelsson, Eriksson \& Lilja, 2012).

On the website of the well-known Drumcafe (www.drumcafe.com) they note the possibilities of using their sessions

- for the opening and closing of conferences,

\footnotetext{
5 'Transformation' is a catchword in democratizing South Africa that refers to the acknowledgement of the humanity of all members of a diverse society.
} 
- for teambuilding and training,

- for awards ceremonies,

- for staff parties and incentive groups.

Why not for meetings, too?

\section{Humour}

This is such an important aspect of the use of music that it is surprising that even less has been written about it, academically, than about the scientific study of the relationship between music and emotion. A great deal of this humorous aspect uses words - so one is mostly talking about songs, and ways in which we can cleverly apply the words of songs to situations (cf. the pop song "I want to break free", for example), modify existing lyrics, writing new ones for specific purposes, or use tunes with referential significance, such as if you know that the title of a certain piece of jazz by Glenn Miller is "In the Mood". Mithen (1998) especially notes the importance of song, and not only for humorous purposes - "the combination of music and language ... song benefits from a superior means of information transmission, compositional language in the form of lyrics ... combined with a degree of emotional expression, from music, that cannot be found in compositional language alone. Moreover, that music is often produced by instruments which, as an extension of the human body in material form, are themselves a product of cognitive fluidity".

Movement and humour to provide stress release can thus be added to our accumulating list of potential benefits accruing from the use of music in meetings.

\section{SUMMARY AND CONCLUSIONS}

Martin (1995, p, 273) refers to "the enormous and unprecedented demand for music in the industrialised countries of the twentieth century". He asks: "Why should this remarkable cultural phenomenon have occurred? After all, in such societies, music is generally considered to belong to the emotional, irrational sphere of human experience, in marked contrast to the scientific and rational principles which have come to dominate. Other areas of 'irrational' thought - religion and magical beliefs for example - have withered in this ideological climate. So why is there such a demand for music? Or, in other words, why do people find it so useful?"

However, do meeting planners generally find music useful, and if not (yet!), why not? Perhaps it is because "standard social and business practices are built on certain assumptions - shared understandings that have evolved from older beliefs and conditions ... For this reason our daily practices feel right and true to us, regardless of whether they have evolved to keep up with the pace of change. In just such a way a business culture arises and perpetuates itself, perhaps long after its usefulness has passed" - so write the Zanders (2000, p.4). 
In a personal email (27.04.07) from Dr Elling Hamso, Managing Partner of the European Event ROI Institute, he wrote: “As you know, 'experiential communication' is the current hype, and the window is thus open for plugging music design for meetings; we have light designers for events, why not music designers?"

\section{Why is music/music-making so seldom used in business meetings?}

Reviewing the observations distributed through the early part of this article, the following deductions can be made:

- Music has been important in human behaviour from pre-historic times.

- Everyone can hear and respond to music. Although many contemporary managers see themselves as consumers of music - via CD player, iPod, etc. - they would not characterise themselves as makers of music.

- Whereas many behavioural impacts of music have been extensively studied, little, if any, specific effort has gone into examining the how and why of music as an essential element in effective business meetings.

- To many, making music involves some form of performance, and they are reluctant to 'compete' with professional music makers who fill the sound space around them.

- Managers have lost sight of the fun and power of music-making, especially singing - which requires no instrument - because they seldom experience the immediacy of the presence of a live singer, and certainly this is the case within a work environment.

\section{The potential benefits of music in business meetings}

- Music can express and influence emotions in a way that language alone cannot and it can be used in meetings, as background or more directly, to arouse emotions or moods that

○ stimulate cooperation

- cue memories of past (good) experiences

o civilise the tone of a discussion and generally help managers to cope with the challenges of cooperation.

- Direct involvement in making music can reduce the boundaries between participants. The outcome is an increase in group trust and a consequential increase in knowledge sharing.

- Music can improve the focus of meeting participants and their grasp and retention of important information.

- Movement with humour provides stress release in meetings.

\section{RECOMMENDATIONS}

Hopefully the above has revealed a range of possibilities for managers to explore in their use of music, which will always need to be tailored to the group of people involved.

Some specific options that can be considered would include: 
1. Identify music that will improve the cooperative or concentration climate in a meeting and have it played at suitable times, either before or during the meeting. Do not hesitate to startle the group with a rousing interlude at 'dozy' times. (Modern meeting rooms usually have suitable audio-visual aids installed.)

2. For community singing, select items to which the majority of the group can respond.

3. When difficult and complex matters are to be discussed, arrange for background music to be played. Focus on instrumental pieces, because verbal content can be distracting.

4. Exploit the ability of music to add a special feelingful element to a message and to assist memory; for instance in helping to convey important messages, such as product features or safety precautions.

5. Use shared musical experiences, e.g. drumming or singing, to reinforce group identity when unusual combinations of persons are attending a meeting, or to revitalise groups whose interactions have become stereotyped.

6. Invite (and reward) musically-oriented staff or their family members to select or compose music that will complement language that expresses a new corporate vision or initiative, and encourage staff to sing the lyrics. Play a recording possibly by a good staff group - in the canteen.

7. Remember that musical performance can increase the focus of attention on the performer, and utilise this fact to your advantage. Find ways of using your own voice to increase the impact of key announcements or events.

8. Experiment with musical interventions and encourage others' efforts to do the same.

Finally, stimulate the judicious use of music in your company to improve the climate for so many aspects of staff behaviour. The enhanced quality of meetings will increase your competitive advantage and business excellence.

\section{REFERENCES}

Benson, J. (1987). Working More Creatively with Groups. London: Routledge.

Benzon,W. L. (2001) Beethoven's Anvil: Music in Mind and Culture. Oxford: Oxford University Press.

Blacking, J. (1973). How Musical Is Man? Seattle: Univ of Washington Press.

Brown, S. (2000). The 'musilanguage' model of human evolution. In The Origins of Music (ed. N. L.Wallin, B. Merker \& S. Brown) , 271 - 300. Cambridge, MA: Massachusetts Institute of Technology.

Cape Argus. (16 Aug 2006). Reuters article on "Stressed bankers learn to sing their blues away". Cape Town, South Africa.

Caporeal, L., Bermudez de Castro, J. M., Arsuage, J.L., Diez, J.C., Rosas, A., CuencaBescós, G., Sala, R., Mosquera, M., \& Rodriguez, X. P. (1995). Lower Pleistocene hominids and artefacts from Atapuerca-TD6. Science 269, 826-30. 
Chung, Y., Hsu, Y., \& Tsai, C. (2010). Research on the correlation between implementation strategies of TQM, organisational culture, TQM activities and operational performance in high tech firms. Informational Technology Journal, 9(8), 1696-1705.

Cross, I. (1999). Is music the most important thing we ever did? Music, development and evolution. In Suk Won Yi. (Ed.), Music, Mind and Science, 10-39. Seoul: Seoul National Univ Press.

Czicksentmihalyi, M. (1990). Flow: The Psychology of Optimal Experience. New York: Harper \& Row.

Dahlgaard-Park, S M. (2012). Core values - the entrance to human satisfaction and commitment. Total Quality Management \& Business Excellence, 23 (2),125 -140.

Dahlgaard, J., Pettersen, J. \& Dahlgaard-Park, S. (2011). Quality and lean health care: A system for assessing and improving the health of healthcare organisations. Total Quality Management \& Business Excellence, 22(6), 673-689.

Duffy, C. \& McEuen, M.B. (2010), The Case for Face-to-Face. [online] Available at http://www.imex-frankfurt.com/documents/FutureofMeetings_Maritz_Nov2010 pdf Accessed 30 January 2012.

Ekman, P. (1992). An argument for basic emotions. Cognition and Emotion 6, 169-200.

Ekman, P \& Davidson, R.J. (1995). The Nature of Emotions: Fundamental Questions. Oxford: Oxford University Press.

Evans, D. (2001). Emotion: The Science of Sentiment. Oxford. Oxford University Press.

Fried, R. \& Berkowitz, L. (1979). Music hath charms and can influence helpfulness. Journal of Applied Social Psychology, 9, 199-208.

Green, T. J. (2012). TQM and organisational culture: How do they link? Total Quality Management \& Business Excellence, 23 (2), 141-157.

Hazlewood, C. (2011). Trusting the Ensemble. TED Talk. http://www.ted.com/talks/lang/en/charles_hazlewood.html . Accessed 29 August 2012.

Ingelsson, P., Eriksson, M. \& Lilja, J. (2012). Can selecting the right values help TQM

Janata, P. \& Grafton, S T.( 2003). Swinging in the brain: shared neural substrates for behaviourts related to sequencing and music. Nature Neuroscience 6, 682-7.

Keil, C. \& Feld, S. (Eds.) (1994). Music Grooves. Chicago: University of Chicago Press.

Kosfeld, M., Heinrichs, M., Zak, P., Fischbacher, U. \& Fehr, E. (2005). Oxytocin Increases Trust in Humans. Nature, 435, 673-676.

Lagrosen, S. \& Lagrosen, Y. (2012). Trust and quality management: Perspectives from

Levitin, D. (2010). The World in Six Songs. London: Aurum Press.

Mandel, S.E. (1996). Music for wellness: music therapy for stress management in a rehabilitation program. Music Therapy Perspectives 14, 14, 38-49.

Martin, P.J. (1995). Sounds and society: Themes in the sociology of music. Manchester: Manchester Univ Press.

McAllester, D.P. (1971). Some Thoughts on "Universals" in World Music. Ethnomusicology, 15 (3), 379-380.

Mithen, S.J. (1998). The supernatural beings of prehistory and the external storage of religious ideas. In Cognition and Material Culture: The Archaeology of Symbolic Storage. (ed.C. Renfrew and C. Scarre) 97-106. Cambridge: McDonald Institute of Archaeological Research. 
Mithen, S. J. (2005). The Singing Neanderthals. London: Phoenix.

Mithen, S. J, \& Parsons, L. (2008). The Brain as a Cultural Artefact. Cambridge Archaeological Journal, 18, 415-422.

Nettl, B 1983. The Study of Ethnomusicology: Twenty-Nine Issues and Concepts. Urbana, Il: University of Illinois Press.

Niedenthal, P. M. \& Setterlund, M. B., (1994). Emotion congruence in perception. Personality and Social Psychology Bulletin. 29. 401-11.

Oatley, K. \& Jenkins, J.J. (1996). Understanding Emotions, Oxford: Blackwell.

Pinker, S. (1997). How the Mind Works. New York: Norton.

Prajogo, D., \& McDermott, C. (2005). The relationship between total quality management practices and organisational culture. International Journal of Operations \& Production Management, 25(11), 1101-1122.

Reimer, B. (2003). A Philosophy of music education: advancing the vision. $3^{\text {rd }}$ Edition. Englewood Cliffs, NJ: Prentice Hall.

Scherer, K.R. \&Zentner, M. R. (2001). Emotional effects of music: production rules. In Music and Emotion: Theory and Research. Ed. P.N. Juslin \& J. A. Sloboda. pp361-92. Oxford: Oxford University Press.

Snowden, D. (2002). "Complex acts of knowing: paradox and descriptive selfawareness". Journal of Knowledge Management, 6 (2), 100-111.

Sunday Times. (2008). Sound of music lowers cholesterol. Article from The Sunday Times, London, reprinted in the South African Sunday Times, 28January.

Sveiby, K-E. (1997). The New Organizational Wealth: Managing and Measuring Knowledge-Based Assets. San Francisco: Berrett-Koehler.

The Economist. (2005). "Twilight of the yobs". The Economist. 8 January, p.36.

Van As, A. (2009). Choir participation as tool for transformation and teambuilding in a corporate environment: a case study within Absa Bank. Unpublished DMus thesis. Pretoria, University of Pretoria.

Zander, R.S. \& Zander, B. (2000). The Art of Possibility. New York: Penguin Books. 